\title{
FISCAL DETERMINANTS OF MIGRATION TO A FAST-GROWING STATE: HOW THE AGED DIFFER FROM THE GENERAL POPULATION
}

\author{
Afsaneh Assadian ${ }^{*}$
}

\begin{abstract}
This paper utilizes 1980-89 data on Florida's metropolitan areas to test the hypothesis that fiscal variables have differing influences on the in-migration of the aged as compared to the general population. The model, which is based on the Tiebout hypothesis, tests the role of variables which represent public school-related finances and public assistance. With the application of a pooled cross-section time series approach, several versions of two equations are estimated using the general linear model. Consistent with the Tiebout theory, the general population is found to prefer high public school-related spending and low taxes. The elderly, in contrast, choose locations where school spending and taxes are low. Nonschool-related taxes positively impact the migration of both groups. Contrary to previous studies, there is evidence of a role, albeit a mostly negative one, for the economic determinants of elderly migration. The possible importance of quality of life influences is also suggested by the findings.
\end{abstract}

\section{INTRODUCTION}

This paper uses data on Florida's metropolitan areas for 1980-89 to examine how the migratory behavior of the aged and the population at large differ, particularly in response to fiscal considerations. In keeping with the Tiebout hypothesis, considerable attention will be directed to public school-related variables.

The premise for this work is the recognition that the elderly, like other age groups, live on fixed budgets and are therefore expected to respond to economic variables-both fiscal and nonfiscal. Moreover, it is expected that private sector concerns such as the availability of employment and wage levels would figure less prominently in their decisions than, for example, property taxes and public assistance. Finally, studying the migration behavior of the elderly has a particular advantage: the group is likely to have more homogeneous preferences than the general population or any other age group. The focalization of elderly migration, an indicator of the group's internal homogeneity, has been documented (Bohland and Treps 1982).

The question being addressed is a particularly pertinent one for Florida, a state that has experienced very high rates of population growth since the turn of the century. During 1980-89 the state's population grew by 31 percent. Through

\footnotetext{
*Assistant Professor of Economics, Florida Atlantic University. I gratefully acknowledge the helpful comments and suggestions of two anonymous referees.
} 
both migration and aging, the portion of the state's elderly population has grown from 11.1 percent in 1960 to 17.8 percent in 1988 (Denslow et al. 1990); the analogous national percentage stood at 11.9 percent in 1985 (Myers, 1990). Whether the experience of Florida is more idiosyncratic than representative of other major destinations is beyond the scope of this work. The growing ranks of the elderly makes their mobility, albeit vis-á-vis a single state, a subject of increasing interest.

For close to four decades the Tiebout theory of population sorting according to local fiscal preferences has formed the dominant paradigm for analyzing interjurisdictional migratory patterns (Tiebout 1956). The theory suggests that households vote with their feet, with low tax and/or high expenditure localities generally holding greater attraction. Put differently, migrants wish to obtain the highest possible fiscal surplus, i.e., the excess of services over tax payments (Riew 1973).

The research on migration, particularly as it pertains to the elderly, has in part stressed the role of social and quality of life (QOL) predictors of migratory behavior, in effect de-emphasizing economic explanations. Those with considerable monetary and time resources-among them a large segment of the aged population ${ }^{1}$-are expected to be particularly responsive to QOL influences. Higher income is viewed as increasing the demand for amenity-oriented activities andgiven the time-intensive nature of these activities-the demand for leisure.

There are several reasons why public finance and QOL influences on mobility are in fact interrelated, particularly in the case of Florida. First, the quality of the public infrastructure, including public schools, is potentially as much of an influence on its QOL as are its unique environmental and geographical features. Second, while the sun and surf might perhaps be the primary magnet, it is the state and local governments that have to muster the resources to cope with the influx. Third, a concern with growth management ${ }^{2}$ has stemmed from the fiscal and environmental problems-such as a greater need for public infrastructure and increasing pollution, congestion and degradation of natural resources-that continue to accompany population and economic growth. The need for such a policy has been reinforced by the fiscal limitations stemming from, for example, the lack of a state income tax as well as the existing decentralized pattern of land use and Florida's special environmental vulnerability. ${ }^{3}$

Locational variations in amenities change the interpretation of the wage gradient from representing a disequilbrium situation that tends to disappear over time with labor mobility (the disequilbrium approach) to compensating differentials that will persist (the equilbrium approach). Roback $(1982,1988)$ has demonstrated that if the amenity is also productive ${ }^{4}-$ i.e., it affects business profits as well as consumer utility-and housing markets are incorporated into the 
analysis, the sign of the wage gradient is ambiguous. Additionally, according to Roback (1988), the amenity differential generates rent differences that tend to be in the opposite direction to the wage differentials. Given that rent is a major determinant of the cost of living, the equalizing wage differential is greater in real terms than in nominal terms.

The interstate experience of Florida-which is potentially informative with regard to intrastate patterns-is indicative of QOL-related compensatory wage differentials. In 1987 the average annual pay in Florida was over 10 percent below the level for the U.S. Kenny (1990) concludes that 10 percent of the Florida-U.S. wage differential can be attributed to Florida's desirable climate. Moreover, consistent with Roback's (1988) analysis, the cost of land, a determinant of rent, is above the national average.

Section II, which contains a review of the relevant literature, is followed by a description of the data and the empirical model in section III. The findings, which appear in section IV, lend some support to the Tiebout hypothesis. Specifically, the general population appears to choose locations with lower public school-related taxes and higher related expenditures. Contrary to much previous research, the elderly are found to be concerned with economic-fiscal and nonfiscal-variables. They prefer school-related taxes and expenditures to be low. The paper concludes with some remarks in section $\mathrm{V}$.

\section{REVIEW OF THE LITERATURE}

The review is divided into migration studies that pertain to the population as a whole and literature focusing on geographical movements of the aged. The former mostly lies within human capital investment theory, while the latter primarily falls in the spheres of social gerontology and demography. Some analysis of interstate mobility is included for its insights on the socioeconomic characteristics of Florida's elderly migrants and how they differ from other age cohorts of migrants.

Research has linked various personal characteristics to migration behavior. These have included gender, education, race, age and previous geographic mobility (Herzog and Schlottmann, 1986). The relevance of sundry other variables, most of which pertain to the geographical unit-typically the metropolitan area-has also been incorporated into the work on migration. In this context, climate, the economic environment, state and local tax rates, and the quality of public services are usually considered.

Pack (1973) analyzes the influence of fiscal variables on in-migration, such as per capita measures of residential taxes and public expenditures and a per 
recipient measure of welfare payments. The local fiscal variables are found to be significant. Cebula's (1974a) estimates of net in-migration to SMSAs show economically advantaged nonelderly migrants to prefer low property tax areas. Herzog and Schlottmann (1986) find evidence of residents of metropolitan areas voting with their feet, with state and local taxes contributing to out-migration. Aggregate studies of migration generally provide evidence of an insignificant or only slightly significant welfare variable (Pack 1973; and see Cebula 1979). Finally, Shaw (1986) posits that the growth in the role of social security-type programs has cushioned and thus generally weakened the impact of market variables such as unemployment.

The various measures of the economic environment such as the actual or potential unemployment rate, the employment rate or its growth and per capita or median income have generally produced inconsistent results. The relationship between unemployment and migration, for instance, is often found to be insignificant or of the unexpected sign when aggregate information is used.

Olvey (1970) and Greenwood (1975) find that employment growth, income, and income growth each positively impact in-migration. The potential for simultaneity is recognized and addressed by several works: job creation, for example, can result from in-migration. The need for some disaggregation by race, income, age, or other indicator of potential welfare recipient status is suggested by Greenwood (1975) and Cebula (1979). Graves $(1979,1980)$ addresses the implications of the changing demand for climate-related amenities. Finally, Porell (1982) finds QOL as well as economic variables to be significant determinants of in-migration.

The theoretical approach to the geographical mobility of the elderly which is of greatest relevance to this study is taxonomic. It identifies three types of elderly migration. The first type is referred to as "amenity migration." It is found to occur soon after retirement, with the migrants generally being married, in good health and of higher income and education levels (Speare and Meyer 1988). The QOL at the destination tends to be of great importance to these migrants, who may view the post-move phase of their life as an extended vacation.

The second type of move-known as "kinship" or "assistance" migration-is associated with the aged person developing a chronic disability which makes everyday household tasks difficult (see Longino 1990). As the problem worsens, it is more likely that a change in living arrangements, such as a move to where the children reside, will follow. In the event that the disability worsens to a level beyond the kins' ability to cope, or no such persons are available, a move to an institutional setting follows.

Florida has experienced a large positive net migration flow consisting of a uniquely substantial flow of in-migrants and a much smaller out-migration flow. Moreover, the return of previous out-migrants-which is usually associated with 
the assistance motivation-does not figure strongly in the state's in-migrantion pattern. A study of New York-Florida migrants suggests that, consistent with the taxonomic approach, the in-migrants tend to be financially better off than the outmigrants (see Longino, 1990).

The relative attractiveness of warmer destinations for the aged is not clearcut. Moreover, while there is some indication that the amenity-related move tends to be to nonmetropolitan areas, the destination in a great many of these cases has been an area with a population just below the minimal size required for a MSA classification (see Longino 1982).

Several studies have found the elderly to be insensitive to fiscal variables. Barsby and Cox (1975) consider the effect of special tax treatment and per capita property tax levels. The influence of the latter variable is also examined by Cebula (1974b). Specifically, Cebula (1974b) finds QOL factors such as the availability of medical care and recreation facilities and favorable climate to be positive influences on elderly in-migration. In contrast, economic variables such as per capita state and local taxes and per capita income do not appear to be important. Using state and county data, respectively, Barsby and Cox (1975) and Bohland and Treps (1982) find the generosity of public assistance to be a poor predictor of elderly migration.

Barsby and Cox (1975) and Chevan and Fischer (1979) show that employment variables are unimportant in explaining elderly migration. In fact, Chevan and Fischer (1979) find retirement to explain elderly migration more than any economic factor. Walker and Price (1975) and Svart (1976) conclude that social and amenity factors play the most important role in these decisions. Finally, cost of living, elderly populations of the origin and destination, the distance to be traveled, place of birth and lifetime migration have been considered as determinants of elderly migration.

\section{DATA DESCRIPTION AND EMPIRICAL MODEL}

This study uses aggregate data on Florida for the $1980-89$ period. ${ }^{5}$ The unit of observation is the metropolitan statistical area (MSA). The labor market characteristic of the MSA is believed to be appropriate. Applying a pooled cross-section time series approach, several versions of a set of equations are estimated using the general linear model as discussed by Kmenta (1971).

All twenty of Florida's MSAs have experienced some population growth over the time period being considered. The rates of growth have ranged from approximately 19 percent each for Gainesville, Miami and Pensacola to 77 percent for Naples. Two reclassifications from nonmetropolitan area to MSA have oc- 
curred during the period being studied. These are the Fort Pierce MSA, consisting of Martin and St. Lucie counties, and the Naples MSA, which corresponds to Collier county. The study uses the post-reclassification set of MSAs. The means and standard deviations for the variables appear in table 1.

TABLE 1

Means and Standard Deviations

\begin{tabular}{lll}
\hline \hline & Mean & $\begin{array}{l}\text { Standard } \\
\text { Deviation }\end{array}$ \\
\hline Mig & 0.122 & 0.084 \\
Elder & 0.162 & 0.068 \\
Inc & 0.00012 & 0.000032 \\
Unemp & 6.433 & 2.325 \\
Opty & 9.422 & 4.601 \\
Aexp & 31.438 & 7.401 \\
Rfter & 32.076 & 13.347 \\
Texp & 15603 & 4384.9 \\
Avalue & $0.92129 \mathrm{E}+8^{*}$ & $0.17582 \mathrm{E}+8$ \\
Qed & 54.721 & 9.260 \\
Ctax & 10.447 & 3.034 \\
Ssi & 16.518 & 11.040 \\
Welf & 25.526 & 3.632 \\
\hline
\end{tabular}

"The abbreviation $0.92129 \mathrm{E}+8$ is to be interpreted as 92129000 . Similar notations are used in Tables 2 and 3. For example, $0.269 \mathrm{E}-03$ (from column (6) of Table 3) would be equivalent to 0.000269 .

One of the two dependent variables is the cumulative net migration (MIG). ${ }^{6}$ That is, the net migration figure for 1982, for example, is inclusive of the net migration for 1981 . The second dependent variable is the 65 -years-and-over age group (Elder).

There has been some debate in the literature concerning the interpretation of the net migration data, and the appropriateness of its use. A high value for net migration could reflect a high in-migration and/or a low out-migration. Given that the intent is to capture only in-migration behavior, there is a potential methodological problem, particularly in view of the apparent positive correlation between in- and out-migration (Mueser and White 1989). Kriesberg and Vining (1978) conclude that for areas that have experienced a net migration gain-such as Florida-there is little association between net migration and out-migration.

The elderly population can change through migration, aging and death. Nationally, new entries into the 65 -and-over age group roughly offset the exits through death; these numbers as a percentage of the aged population are approximately 7 and 5 percent, respectively (Myers, 1990). Extrapolating to Florida, 
it is assumed that the growth in the State's elderly population primarily reflects inmigration.

A first difference specification is adopted in order to deal with potential autocorrelation and certain specification and estimation biases pertaining to unmeasured characteristics such as amenities (see Mueser 1989). Two general kinds of explanatory variables are utilized. First, there are the variables that represent the presence or absence of economic opportunities. These are per capita real income measured on a place-of-residence basis and the unemployment rate. Income measures earnings prospects at the destination, and the unemployment rate represents the lack of employment opportunities. A higher unemployment rate suggests a longer job search period upon arrival and hence is believed to act as a deterrent to migration.

Second are a set of variables that represent the provision, quality and financing of public services, especially education. Revenue for public education is measured by the ratio of the operating tax yield of the property tax to personal income (Opty) or by the real revenue from all levels of government per full-time equivalent student or FTE (Rfter). Expenditure on public education is represented alternatively by expenditure on teachers' salaries as a ratio of personal income (Texp) or all public school expenses per FTE (Aexp). Ctax is total ad valorem taxes levied by the county government as a proportion of personal income.

In accordance with the Tiebout hypothesis, it is posited that the greater financial burden from higher taxes discourages migration. In contrast, higher expenditures on education and other public services add to the average citizen's welfare, thus encouraging migration. Similarly, migration is believed to be positively influenced by the quality of the educational system.

Households with school age children are expected to choose jurisdictions that they view as providing the best quality education for the given taxes. Strictly speaking, the testing of such hypotheses requires the use of disaggregate data which can distinguish between those with and without children. However, given the absence of school age children from elderly households, a qualified comparison across the two samples is valid.

Real Supplemental Security Income per case (Ssi) or real average annual payment to families with dependent children-known as welfare-(Welf) were included in order to represent the generosity of public assistance programs. Since the former is for the aged as well as the blind and the permanently disabled, of the two transfer programs, it is expected to result in a greater (smaller) positive (negative) relative response from the elderly. Both variables can also act as proxies for the rate of poverty. Specifically, where poverty is more acute the average payment per case is likely to be greater, i.e., recipients will generally remain on the rolls for a longer period of time. 
Noting that the tax liability on a given piece of property is determined as the product of the assessed value and the statutory tax rate, a further hypothesis is tested: that a negative tax variable coefficient represents an objection to high or unfair property value assessments. To this end, one set of regressions includes, as explanatory variables, the assessed value of single-family residential property as a ratio of real personal income (Avalue). ${ }^{7}$ The hypothesis being tested is that, where the tax revenue variable is negative, it represents an objection to high or unfair property value assessments. This interpretation is in line with the misgivings that the public is believed to have about the property tax, viewing it as based on incompetently and unfairly arrived-at assessed values (Aaron 1975). A negative impact is also expected because property values represent a major component of the cost of living.

Finally, a variable that is expected to capture the influence of education quality (Qed) is included. Qed is measured as the percentage of high school graduates who immediately pursue further education.

The estimates are based on the following equations:

$$
\begin{aligned}
& (\mathrm{Mig})^{*}=\mathrm{a}_{0}+\mathrm{a}_{1}(\mathrm{Inc})^{*}+\mathrm{a}_{2}\left(\mathrm{Unemp}^{*}\right)^{*}+\mathrm{a}_{3}(\mathrm{Schl})^{*} \\
& +a_{4}(\text { Qed) })^{*}+a_{5}(\text { Ctax })^{*}+a_{6} \text { (Asst) }^{*} \\
& (\text { Elder })^{*}=b_{0}+b_{1}(\text { Inc })^{*}+b_{2}\left(\text { Unemp }^{*}+b_{3}(\text { Schl })^{*}\right. \\
& +\mathrm{b}_{4}(\mathrm{Qed})^{*}+\mathrm{b}_{5}(\mathrm{Ctax})^{*}+\mathrm{b}_{6}(\text { Asst })^{*}
\end{aligned}
$$

where $(\operatorname{Inc})^{*}$, for example, is given as $(I n c)^{*}=I n c_{i}-I n c_{i-1}$ where $i$ and $i-1$ are two sequential observations, typically time periods, and Schl represents any of the public school-related fiscal variables including Avalue, and Asst is either Ssi or Welf.

\section{FINDINGS}

The estimation findings are presented in Tables 2 and 3. Table 2 shows the coefficients for both versions of the Asst variable and uses Opty or Aexp as the Schl variable. Table 3 provides additional findings for the version with Ssi as the Asst variable. The purpose of presenting a variety of findings is to discern the general pattern of results and to demonstrate their insensitivity to the particular specification. There are two noteworthy consequences to the adoption of the first difference approach. First, there is no intercept term. Second, the adjusted $R^{2}$ is not well defined. The $R^{2} s$ shown in Tables 2 and 3 are raw-moment $R^{2} s$, which tend to overstate the true goodness of fit. 


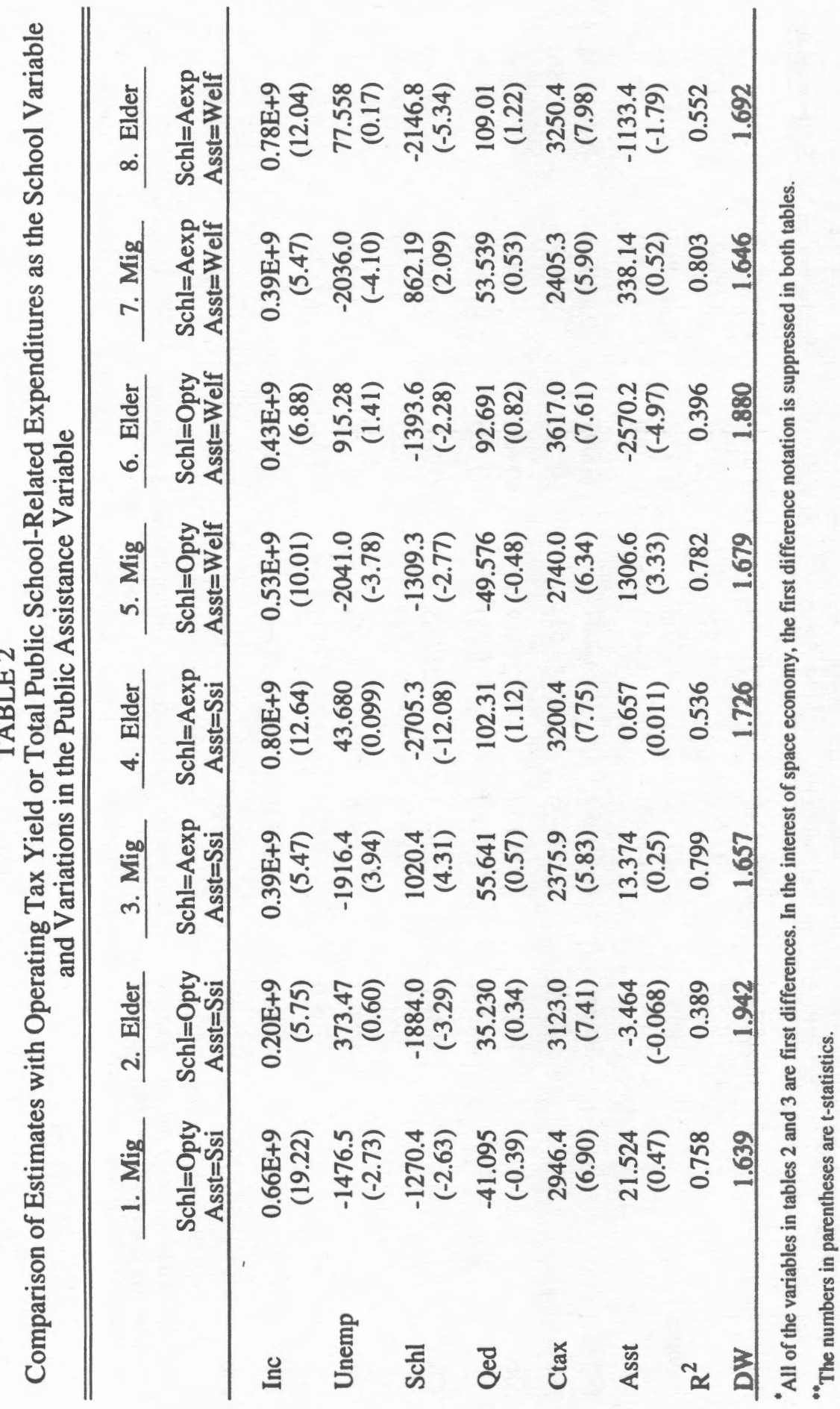




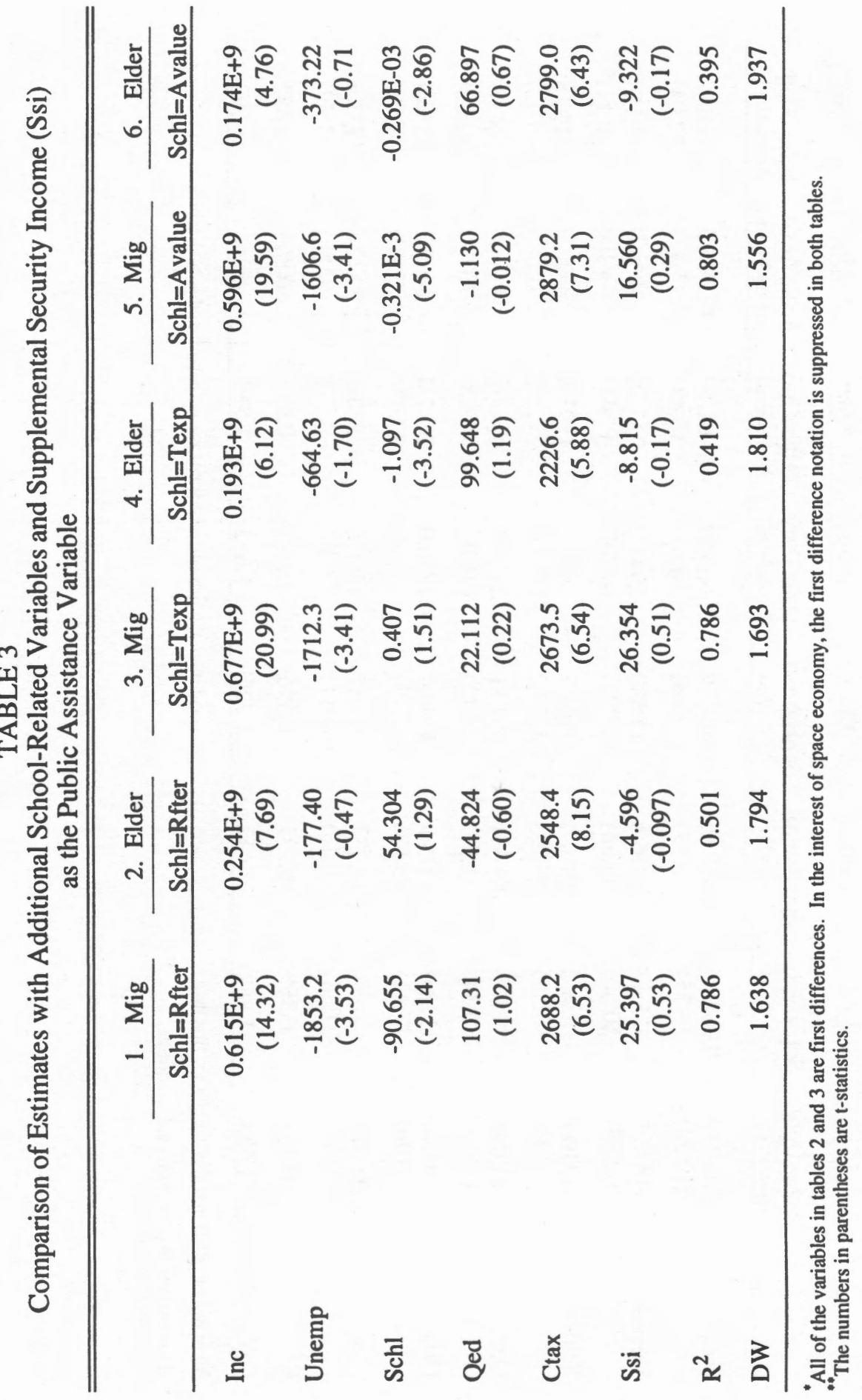


There has been some debate in the literature concerning the correct interpretation of the labor market-related variables. Graves (1980) has suggested that, in the absence of controls for the importance of climate and contrary to the disequilbrium approach, income and unemployment are expected to have negative and positive estimated coefficients, respectively. Mueser (1989) questions the view of a positive coefficient for the income variable as indicative of a preference for higher wages. The alternative interpretation put forward is one of migration responding to recently improved employment opportunities that are the outcome of the same market forces that raise wages.

The estimates for both income and unemployment from Tables 2 and 3 correspond to the disequilbrium view, with the conclusion being less decisive in the case of the elderly. Improved job market opportunities appear to encourage greater in-migration. In fact, the positive income estimates for the elderly are perhaps puzzling in light of their overwhelming lack of labor market participation. A spurious relationship may exist if higher income households are more likely to demand a better QOL and given that the latter is directly related to in-migration.

The total public school spending per FTE (Aexp) estimates are positive and significant for the whole population. In contrast, for the elderly sample Aexp and the alternative measure of public school spending-teachers' salaries as a ratio of personal income (Texp)-are negative and significant. The negative coefficients for the revenue per FTE (Rfter) and the operating tax yield (Opty) point to an aversion to high tax areas by the general population and the elderly. Moreover, the Opty estimates are also in line with those of the assessed value (Avalue), a point which will be discussed below. Finally, the migration of the general population and the elderly are both positively related to county taxes. Given the absence of adequate controls for nonschool spending, the positive coefficient of this variable could be capturing the impact of the high spending levels that are facilitated by high tax revenues.

There is limited evidence that the welfare program is viewed by the total population as having net benefits. The negative coefficient for Asst in column (6) of Table 1 suggests that from the elderly's perspective the program is primarily a cost, even if, for altruistic or other reasons, they attribute some benefits to it. The estimates can also be interpreted as showing an aversion on the part of the elderly, but not the general population, to locating in jurisdictions with a high rate of poverty.

It can be posited that households are more aware of, and therefore opposed to, the property tax than, for example, the federal income and payroll taxes. Both the discrete, often annual, nature of property tax payments and the absence of an intermediary (the employer) permitting gradual payment would suggest that the taxpayer is more cognizant of the burden of the latter. 
The assessed value (Avalue) estimates do bear out the expectation of an aversion to high assessed values and/or the high cost of living that high property values partially determine. These results reinforce the finding of a negative impact from the Opty variable, which is in effect the product of the assessed value and the statutory tax rate. To elaborate, the negative effect of Avalue and its consistency with the Opty estimates suggest that potential residents may in fact be concerned with high assessed values, rather than with high tax rates. The education quality variable is insignificant.

\section{CONCLUDING REMARKS}

The main findings of this research can be summarized as follows. First, the nonfiscal economic variables-income and unemployment-have the signs predicted by the disequilbrium model, with the income variable also possibly being indicative of a role for QOL. Given the elusive nature of QOL and the paucity of related data, such indirect inferences are the best that can usually be hoped for. Second, local taxes and spending do impact location decisions as predicted by the Tiebout hypothesis. While migrants in general favor high levels of school spending, the elderly tend to gravitate towards MSAs with lower public school-related spending. Both groups prefer low tax jurisdictions, a result which could perhaps indicate a preference for lower assessed values rather than lower tax rates. The former interpretation is supported by negative estimates for both assessed values and operating tax yields.

Third, the negative association between in-migration and assessed values may also reflect migrants' concerns with the high cost of living, which is in part determined by high property values. Fourth, for both groups, county taxes, which have broader benefits for residents than school-specific taxes and spending, encourage inmigration. Fifth, there is some limited evidence that public assistance payments per recipient attract the general population but might discourage the elderly. Finally, the small explanatory power of economic (including fiscal) variables in the elderly equations is further indication of a possible role for quality-oflife influences. Clearly, given the projected demographic changes, the contrasting migration decisions of the elderly and nonelderly populations are expected to remain of considerable research interest in both inter- and intrastate contexts. 


\section{ENDNOTES}

1. The elderly as a group have experienced a marked improvement in their economic status in recent years. Using a measure of income that is inclusive of implicit rent, mean and median values for elderly income relative to nonelderly income are found to be 1.05 and 0.99, respectively, in 1986 (Smeeding 1990).

2 Florida's Local Government Comprehensive Planning and Land Development Regulations Act, better known as the Growth Management Act of 1985, was conceived in response to a perceived need to reign in development, bringing it in line with the availability of fiscal resources, and to create new sources of revenue. The Act requires the "concurrency" of new development with the availability of public infrastructure. The issue of inadequate government funds is addressed by giving local governments the authority to impose impact fees on the developers.

3. The environmental features that set Florida apart include the peninsula formation, the wetland ecosystem with its critical role as a source of potable water, and presence of the only living coral reef off the United States. Environmental concerns go beyond the directly aesthetic. Coastal erosion, which threatens beachfront development, has costly remedies. Development has required the draining of the wetlands and has resulted in pollution of underground supplies of water. Even what might seem to be purely aesthetic-the coral reef-has potential economic consequences, given that people are attracted to the state in large measure because of its high QOL.

4 Roback (1982) uses "lack of severe snow storms" as an example of a productive amenity.

5. College of Business Administration, University of Florida, Bureau of Economic and Business Administration, Florida Statistical Abstract 1991 and previous editions.

6. The use of a cumulative measure is preferable, since it renders the total population data more comparable to the elderly population data. As is apparent from further discussion in this section, the latter is providing a cumulative measure of net elderly migration.

7. The assessed value, known as the just value, is determined for the highest and best use of property. It differs from the taxable value of property, the latter being arrived at after the subtraction of exemptions. The expressing of assessed value as a ratio of real, rather than nominal, income is believed to be preferable, as it allows the gauging of the effect of property values through its impact on the cost of living. 


\section{REFERENCES}

Aaron, Henry J. Who Pays the Property Tax? A New View. Washington, D.C.: Brookings Institution, 1975.

Barsby, S. L., and D. R. Cox. Interstate Migration of the Elderly. Lexington, Mass.: Lexington Books, D. C. Heath and Company, 1975.

Bohland, James R., and Lexa Treps. "County Pattern of Elderly Migration in the United States." In A.M. Warnes (ed.). Geographical Perspectives on the Elderly. New York: John Wiley and Son, 1982.

Cebula, R. J. "Interstate Migration and the Tiebout Hypothesis: An Analysis According to Race, Sex, and Age." Journal of the American Statistical Association 69 (1974a): 876-879.

Cebula, R. J. "The Quality of Life and Migration of the Elderly." Review of Regional Studies 4 (1974b): 62-68.

Cebula, R. J. "The Migration Impact of Public Policies: A Critique of the Literature." In The Determinants of Human Migration. Lexington, Mass.: Lexington Books, D.C. Heath and Company, 1979.

Chevan, A., and L. R. Fischer. "Retirement and Inter-State Migration." Social Forces. 57 (1979): 1365-80.

Denslow, David A., Ann C Pierce and Ann H. Shermyen, (eds.) The Economy of Florida 1990 Edition. Gainesville: University Presses of Florida, 1990.

Graves, Philip E. "Income and Migration Reconsidered." Journal of Human Resources 14 (1979): 112-121. "Migration and Climate." Journal of Regional Science 20, 2 (1980).

Greenwood, M. J. "A Simultaneous-Equations Model of Urban Growth and Migration." Journal of the American Statistical Association 70 (1975): $797-$ 810.

Herzog, Henry W., and Alan M. Schlottmann. "State and Local Tax Deductibility and Metropolitan Migration." National Tax Journal 39 (1986): 189-200.

Kenny, Lawrence W. "The Labor Market." In David A. Denslow et al. (ed.). The Economy of Florida 1990 Edition. Gainesville: University Presses of Florida, 1990.

Kmenta, Jan. Elements of Econometrics. New York: Macmillan, 1971.

Kriesberg, E. M., and D. R. Vining. "On the Contribution of Out-Migration to Changes in Net Migration: A Time Series Confirmation of Beale's CrossSectional Results." Annals of Regional Science 12 (1978): 1-11.

Longino, Charles F. Jr. "American Retirement Communities and Residential Relocation." In A. M. Warnes (ed.). Geographical Perspectives on the Elderly. New York: John Wiley and Son, 1982. 
Longino, Charles F. Jr. "Geographical Distributiom and Migration." In Robert H. Binstock and Linda K. George (eds.). Handbook of Aging and the Social Sciences. San Diego, California: Academic Press, 1990.

Mueser, Peter R. "Measuring the Impact of Locational Characteristics on Migration: Interpreting Cross-Sectional Analyses." Demography 26, 3 (1989): 499-513.

Mueser, Peter R., and Michael J. White. "Explaining the Association Between Rates of In-Migration and Out-Migration." Papers of the Regional Science Association 67(1989): 121-134.

Myers, George C. "Demography of Aging." In Robert H. Binstock and Linda K. George (ed.). Handbook of Aging and the Social Sciences. San Diego, California: Academic Press, 1990.

Oates, W. E. "The Effects of Property Taxes and Local Public Spending on Property Values: An Empirical Study of Tax Capitalization and the Tiebout Hypothesis." Journal of Political Economy 77 (1969): 957-970.

Olvey, L. D. Regional Growth and Inter-Regional Migration-Their Pattern of Interaction. Ph.D. dissertation, Harvard University, 1970.

Pack, J. R. "Determinants of Migration to Central Cities." Journal of Regional Science 13 (1973): 249-260.

Porell, Frank W. "Intermetropolitan Migration and Quality of Life." Journal of Regional Science 22, 2 (1982): 137-158.

Riew, J. "Migration and Public Policy." Journal of Regional Science 13 (1973). 65-76.

Roback, Jennifer. "Wages, Rents, and the Quality of Life." Journal of Political Economy 90, 6 (1982).

Roback, Jennifer. "Wages, Rents and Amenities: Differences Among Workers and Regions." Economic Inquiry 26 (1988): 23-41.

Shaw, Paul R. "Fiscal versus Traditional Market Variables in Canadian Migration." Journal of Political Economy 94, 3: 649-67.

Smeeding, Timothy. "Economic Status of the Elderly." In Robert H. Binstock and Linda K. George (eds.). Handbook of Aging and the Social Sciences. San Diego, California: Academic Press, 1990.

Speare, A. Jr., and J. W. Meyer. "Types of Elderly Residential Mobility and Their Determinants." Journal of Gerontology: Social Sciences 43 (1988): S74-S71.

Tiebout, Charles M. "A Pure Theory of Local Expenditures." Journal of Political Economy 64 (October 1956): 416-424.

Svart, L. M. "Environmental Preference Migration: A Review." The Geographical Review 66 (1976): 314-30.

Walker, J., and Price, K. "Retirement Choice and Retirement Satisfaction." The Gerontologist 15, 50 (1975). 